\title{
Malaria transmission blocking immunity and sexual stage vaccines for interrupting malaria transmission in Latin America
}

\author{
Myriam Arévalo-Herrera' ${ }^{1,2,4}{ }^{+}$, Yezid Solarte', Catherin Marin ${ }^{2}$, Mariana Santos $^{2}$, \\ Jenniffer Castellanos ${ }^{2}$, John C Beier ${ }^{3}$, Sócrates Herrera Valencia ${ }^{1,2,4}$ \\ ${ }^{1}$ Institute of Immunology, Faculty of Health, Universidad del Valle, Cali, Colombia \\ ${ }^{2}$ Malaria Vaccine and Drug Development Center, Cali, Colombia \\ ${ }^{3}$ Department of Epidemiology and Public Health, University of Miami Miller School of Medicine, Miami, FL, USA \\ ${ }^{4}$ Centro Latino Americano de Investigación en Malaria, Cali, Colombia
}

\begin{abstract}
Malaria is a vector-borne disease that is considered to be one of the most serious public health problems due to its high global mortality and morbidity rates. Although multiple strategies for controlling malaria have been used, many have had limited impact due to the appearance and rapid dissemination of mosquito resistance to insecticides, parasite resistance to multiple antimalarial drug, and the lack of sustainability. Individuals in endemic areas that have been permanently exposed to the parasite develop specific immune responses capable of diminishing parasite burden and the clinical manifestations of the disease, including blocking of parasite transmission to the mosquito vector. This is referred to as transmission blocking (TB) immunity (TBI) and is mediated by specific antibodies and other factors ingested during the blood meal that inhibit parasite development in the mosquito. These antibodies recognize proteins expressed on either gametocytes or parasite stages that develop in the mosquito midgut and are considered to be potential malaria vaccine candidates. Although these candidates, collectively called TB vaccines $(T B V)$, would not directly stop malaria from infecting individuals, but would stop transmission from infected person to non-infected person. Here, we review the progress that has been achieved in TBI studies and the development of $T B V$ and we highlight their potential usefulness in areas of low endemicity such as Latin America.
\end{abstract}

Key words: malaria - Plasmodium - vaccines - transmission blocking immunity transmission blocking vaccine - vector-borne disease

Malaria parasites are transmitted by Anopheles mosquitoes in nearly 90 countries located in the poorest regions of the world, where approximately 2.5 billion people are exposed to Plasmodium falciparum and Plasmodium vivax infection (Guerra et al. 2008). P. falciparum is responsible for $80 \%$ of the $300-500$ million malaria cases reported every year, most of which $(80 \%)$ occur in Africa. $P$. vivax infection is predominant in the Middle East, Asia, Western Pacific and in Central and South America and it is responsible for 70-80 million cases per year (WHO 2010). In most $P$. vivax endemic regions, the two parasites coexist and both may be transmitted by the same mosquito vectors (Snounou 2004), leading to an undetermined number of mixed infections. Although current malaria control measures targeting the mosquito vector and the parasite have helped eliminate malaria in numerous endemic areas (Genton et al. 2008, Greenwood et al. 2008), the emergence and rapid spreading of insecticide-resistant mosquitoes and increases in parasite resistance to multiple drugs have contributed to malaria increases for decades (WHO 2010).

Financial support: COLCIENCIAS (6124-05-17593/256-2005, 433-2008, 622-2008, 409-2009, 152-2010, 250-2011), NHLBI/NIH (RHL086488A), NIAID/NIH: TMRC (AI49486-01), ICEMR, CLAIM (U19AI089702)

+ Corresponding author: marevalo@inmuno.org

Received 6 April 2011

Accepted 13 July 2011
Failure of these important control tools has prompted the development, implementation and sustained application of new and more cost-effective control measures, including the use of long-lasting insecticide-impregnated bed-nets and new antimalarial drugs (Kelly-Hope et al. 2008, WHO 2010). Vaccines are a promising avenue for the future of malaria control, because how cost effective vaccines have proven to be for controlling other pathogens and because they would act as a complement to the current antimalarial arsenal (Richie \& Saul 2002, Moorthy et al. 2004).

Although malaria cases increased during the second half of the past century, during the last decade they have been on the decline. The factors responsible for this decrease have not yet been identified, but they have created a growing optimism during the last few years about the possibility of eliminating malaria in multiple regions of the globe. A total of 39 Latin America (LA) countries, including Argentina, Mexico, Costa Rica, El Salvador and Guatemala, as well as island countries from the Caribbean, Africa and Oceania, have embarked on elimination programs (Feachem \& Phillips 2009). In Central America, for example, between 2000-2008, all countries decreased malaria incidence by over $50 \%$ and some of the countries in the region, such as Belize, Costa Rica, El Salvador and Nicaragua, have decreased malaria incidence by more than $90 \%$ (WHO 2010). Although this dramatic result has been achieved with currently available control measures, for new malaria elimination and eradication efforts, new tools and a comprehensive research agenda must be devel- 
oped (Alonso et al. 2011b). Among the tools being studied, vaccines that could interrupt transmission are considered a priority (Alonso et al. 2011a).

Malaria vaccine development is based on the observation that individuals permanently exposed to malaria infections in endemic areas eventually develop clinical immunity that significantly limits the intensity of the disease and reduces mortality. In these areas, children are highly susceptible to severe disease and death, but adults frequently harbour asymptomatic infections that allow them to lead an almost normal life (Greenwood et al. 2005). Additionally, the observation that sera from these immune individuals can also block the fertilization of gametes and prevent further parasite development, thus interrupting parasite transmission from patients to mosquito, provides the basis for the feasibility of transmission blocking (TB) vaccines (TBV) (Greenwood et al. 2005, 2008). These findings have stimulated research into the human immune mechanisms involved in protection against infection and disease (Girard et al. 2007, Targett \& Greenwood 2008) and in the blockage of parasite transmission from host to mosquito (Reed et al. 2006, Smith et al. 2011).

Parasite fertilization in the mosquito midgut can be blocked by specific antibodies complement and cytokines, which inhibit oocyst formation and subsequent development in the sporogonic cycle within the mosquito midgut (Sutherland 2009, Sinden 2010). Much effort has been invested in searching for the parasite targets of those protective responses, which could be used to design malaria vaccines (Alonso et al. 2011a). Several of the candidate genes have been expressed as recombinant products and both protein and DNA-based vaccine sub-units have been designed and tested in animals and humans (Doolan \& Hoffman 2001). Most of the vaccine candidates that have been tested are immunogenic and maintain at least a partial capacity to prevent the infection, reducing blood infection and eliciting antibodies that blocked parasite transmission to the mosquito (Alonso et al. 2011a, Smith et al. 2011).

This review addresses the natural immune response against the sexual parasite forms found in individuals exposed to both the $P$. vivax and the $P$. falciparum malaria parasites, as well as addresses the studies carried out in both experimental animal models and humans and their potential use for the design of TBV. We review the potential usefulness of these vaccine candidates for eliminating malaria in LA.

Role of immune responses in blocking parasite transmission to mosquito - The sporogonic phase of the Plasmodium life cycle is initiated in the mosquito midgut by fertilizing sexually differentiated parasites. Male and female gametes fuse to produce zygotes that transform into motile ookinetes, which further develop into oocysts in the epithelium of the mosquito midgut. Each mature oocyst produces an abundant number of sporozoites that migrate from the midgut to the salivary gland and are eventually injected into the blood circulation during a mosquito blood meal, stimulating an infection in the vertebrate host (Aly et al. 2009).
After repeated exposure, individuals from malaria endemic areas develop both humoral and cellular immune responses against proteins expressed in the different forms of the parasite (Girard et al. 2007). The mosquito ingests antibodies specific to sexual stage antigens and other products of the vertebrate immune system, such as cytokines and complement, during the blood meal. Once in the mosquito midgut, these immune molecules interfere with the development of the sporogonic cycle (Peiris et al. 1988, Naotunne et al. 1991, Healer et al. 1999).

Although the role of cytokines in TB immunity (TBI) is not completely understood, it has been observed that both monkeys and humans infected with Plasmodium cynomolgy and $P$. vivax, present peaks of parasitemia associated with an increase in cytokines such as tumor necrosis factor-alpha (TNF- $\alpha$ ) and interferon gamma (IFN- $\gamma$ ). Gametocytes suffer a crisis during this period, which is associated with a decreased ability to infect the mosquito. This loss of infectivity is believed to be associated with the cytokine increases together with humoral or extracellular factors produced by peripheral blood mononuclear cell (Naotunne et al. 1991, Carter \& Mendis 1992).

Although the molecular mechanisms of TBI are not yet clearly understood, sera from individuals in malaria endemic areas are able to block malaria transmission (Mendis et al. 1987, Gamage-Mendis et al. 1992, ArevaloHerrera et al. 2005a, b, 2011, Smith et al. 2011). IgG antibodies purified from these individuals are able to block gamete fertilization and further development of zygotes and ookinetes during the post-fertilization process in the mosquito midgut. These antibodies block the interaction of specific molecules required for gamete interactions during the fertilization process (Lavazec \& Bourgouin 2008, Sutherland 2009, Arevalo-Herrera et al. 2011).

Moreover, IgG antibodies may activate the complement system to induce lysis of mature gametes and zygotes. Additionally, some immune factors such as IFN- $\gamma$ and TNF- $\alpha$, cytokines abundantly produced during patient's paroxysms, are associated with a reduction in gametocyte infection of mosquitoes (Naotunne et al. 1993). These factors also appear to interfere with gamete fertilization, ookinete motility and parasite penetration into the mosquito midgut epithelial cells (Kaslow 1990, Kaslow \& Shiloach 1994). It has been postulated that these cytokines, nitric oxide (NO) and possibly other factors generated in the vertebrate host induce the apoptosis of zygotes and ookinetes (Luckhart et al. 1998, Al-Olayan et al. 2002). NO has been demonstrated to induce a loss of gametocyte infectivity and inhibition of NO-synthase significantly decrease the blocking effect (Cao et al. 1998).

The serum complement system involvement in TB production was first demonstrated in Plasmodium gallinaceum, in which it was shown that newly fertilized zygotes were susceptible to destruction by the alternative complement pathway. Further studies demonstrated that $P$. gallinaceum mature sporozoites that were derived from mosquito salivary glands could be lysed by anti-sporozoite antibodies from the sera of malaria-immunized chickens (Grotendorst et al. 1986, Grotendorst \& Carter 1987). 
This lysis could be abrogated by ethylene glycol tetraacetic acid, which induces calcium depletion and therefore inhibits complement activation (Touray et al. 1994).

Other studies have demonstrated that sera of humans exposed to $P$. falciparum contain $\operatorname{IgG}$ antibodies that recognize sexual stage antigens such as Pfs 230 and Pfs $48 / 45$, which fix the complement and do not block parasite development unless the complement is present (Read et al. 1994, Roeffen et al. 1995). Although some monoclonal antibodies (MAbs) specific for Pfs $48 / 45$ are able to block parasite infection of mosquitoes without a complement, others are dependent on its presence (Carter et al. 1990). The IgG isotype produced in response to a specific immunogen has been observed to depend on both the route of immunization and the vaccine formulation. Mouse experiments using a DNA 230 Pf-glycosyl-phosphatidyl-inositol (GPI) moiety vaccine induced different $\operatorname{IgG}$ isotypes based on the vaccine formulation and the vaccination route. Intramuscular injection preferentially induced complement activating IgG1 and IgG2a isotypes (Fanning et al. 2003). Recent studies using specific gene disruption in parasite clones, such as $p f s 230$ and $p f s 48 / 45$, have shown that it was possible to study not only their function in the mosquito midgut, but also their role in complement-mediated TB. Pfs 230 was found to be not only critical for oocyst production but also cloned with gene disruption retained resistance to the alternative complement cascade, indirectly indicating that, under normal conditions, this protein would be able to activate the complement pathway (Eksi et al. 2006).

Induction of TBI in areas of high and low malaria transmission intensity - The level of naturally acquired TBI can be estimated by the proportion of sera displaying transmission-reducing activity in a given human population and is measured using the standard mosquito membrane feeding assay (SMFA) (van der Kolk et al. 2005) and the direct MFA (Mulder et al. 1999).

TBI appears to depend on the malaria transmission intensity in areas such as Papua New Guinea (PNG) because in areas where malaria is highly endemic, the prevalence of TB activity was $75 \%$ for $P$. falciparum. Whereas in Sri Lanka, which has a lower malaria prevalence, sera from patients with acute primary $P$. falciparum infections revealed that the prevalence of TB activity was $56 \%$, suggesting that the generation of TBI requires prolonged exposure to multiple malaria inoculations (Premawansa et al. 1994). These results appear to agree with studies on naturally acquired immune responses to $P$. falciparum sexual stage antigens conducted in Tanzania, where it was observed that sera from individuals exposed to malaria contained antibodies against Pfs 230 and Pfs $48 / 45$, two parasite proteins expressed on the P. falciparum gametocyte surface. These antibodies increased with the duration of gametocyte exposure and were associated with levels of TB activity reaching greater than $90 \%$ (Bousema et al. 2010). However, studies carried out in Senegal and Cameroon conflict with this observation. In Cameroon, where malaria transmission is high, the levels of gametocytemia are low, whereas in Senegal, where malaria transmission is significantly lower, the percentage of gametocytes is higher. In these studies it was demonstrated that TB is higher in Senegal, where in theory there would be lower antibody titres due to lower exposure of the community to malaria parasites (Boudin et al. 2005).

In principle, TBI depends on the presence of gametocytes in the human peripheral blood circulation, age, the number of previous malaria infections and antibody titres. Antibody titres are correlated with the time of exposure to gametocytes and the number of gametocytes developed during the infections; and sera of individuals with high antibody concentrations are more efficient at blocking parasite transmission to the mosquito. TBI does not increase with age and tends to be higher in younger people (Boudin et al. 2004, Dawes et al. 2009, Bousema et al. 2011).

Paradoxically, some sera containing low concentrations of specific antibodies actually enhance parasite transmission instead of inducing a low-level TB effect. This enhancement is particularly evident in the sera of patients with recent infections (Gamage-Mendis et al. 1992, Ramsey et al. 1996). It has been observed that, in these patients, subsequent infections increase both antibody levels and the parasite TB activity (Ranawaka et al. 1988).

Another relevant aspect of TBI is its duration. TBI responses appear to be short-lived and do not depend on the malaria transmission intensity. In PNG and Colombia it has been estimated that TBI lasts for less than four months, whereas in Mexico and Sri Lanka, which have lower malaria transmission intensities, the reported duration is six months (Premawansa et al. 1994, Ramsey et al. 1996, Arevalo-Herrera et al. 2011). Likewise, the levels of antibodies against Pfs 230 and Pfs $48 / 45$ presented similar half-life ( 3 months), but titres could be boosted by exposure to gametocytes in further infections (Bousema et al. 2010). These studies have been conducted independently and multiple factors, such as the diversity of vector species as well as of Plasmodium strains circulating in different endemic regions, may be affecting the results (Dawes et al. 2009, Bousema et al. 2011).

In LA, only three studies, one in Mexico and two in Colombia, have been reported, (Table I) likely due to the difficulty of establishing of Anopheles mosquito colonies and the lack of SMFA (Solarte et al. 2011). In these studies, the levels of TB have been determined in both infected and uninfected individuals who have been exposed to $P$. vivax and $P$. falciparum, with the latter being more highly prevalent (Ramsey et al. 1996, Arevalo-Herrera et al. 2005b, 2011). In Mexico, 23\% of 104 sera samples studied enhanced transmission and correlated with patients who only had a $P$. vivax malaria event. These samples were not correlated with antibody titres, but levels of TBI were correlated with the presence of the complement and the time between primary and secondary infections (Ramsey et al. 1996). In one of the Colombian studies, which used the sera of $P$. vivax-infected patients $(\mathrm{n}=88)$, $22.7 \%$ had high TB activity, $36.4 \%$ had an intermediate level, $29 \%$ had low blocking activity and $17 \%$ of them induced transmission enhancing. The level of TB was associated with ethnicity, fever and level of antibodies against the parasite blood forms (Arevalo-Herrera et al. 2005c). In the second study, conducted on individuals exposed to 
TABLE I

Studies on transmission blocking (TB) activity in low to moderate malaria transmission areas of Latin America

\begin{tabular}{|c|c|c|c|c|c|}
\hline \multirow[b]{2}{*}{ Study site } & \multirow[b]{2}{*}{$\begin{array}{l}\text { Malaria infection } \\
\text { (subjects) }\end{array}$} & \multicolumn{2}{|c|}{ TB activity } & \multirow[t]{2}{*}{ TB } & \multirow[b]{2}{*}{ Reference } \\
\hline & & $\begin{array}{c}\text { Infected } \\
\text { mosquitoes } \\
(\%)\end{array}$ & $\begin{array}{c}\text { Oocyst } \\
\text { mean } \\
(\%)\end{array}$ & & \\
\hline \multirow{5}{*}{$\begin{array}{l}\text { Southern coast } \\
\text { (Mexico) }\end{array}$} & Acutely infected: & & & & Ramsey et al. (1996) \\
\hline & primary cases $(\mathrm{n}=63)$ & 11 & - & - & \\
\hline & secondary cases $(n=24)$ & 23 & - & TE & \\
\hline & thirdary cases $(\mathrm{n}=17)$ & 2.5 & - & - & \\
\hline & & 2.6 & - & - & \\
\hline \multirow{5}{*}{$\begin{array}{l}\text { Pacific coast } \\
\text { (Colombia) }\end{array}$} & Acutely infected & & & & Arevalo-Herrera et al. (2005c) \\
\hline & (88 patients) & 23 & 36 & HTB & \\
\hline & & 17 & 30 & ITB & \\
\hline & & 42 & 17 & LTB & \\
\hline & & 18 & 17 & $\mathrm{TE}$ & \\
\hline \multirow{5}{*}{$\begin{array}{l}\text { Pacific coast } \\
\text { (Colombia) }\end{array}$} & Non-infected & & & & Arevalo-Herrera et al. (2011) \\
\hline & (44 malaria exposed) & 11.4 & 6.8 & НТВ & \\
\hline & & 15.9 & 9.1 & ITB & \\
\hline & & 29.5 & 36.4 & LTB & \\
\hline & & 43.2 & 47.7 & $\mathrm{TE}$ & \\
\hline
\end{tabular}

HTB: high TB (90-100\%); ITB: intermediate TB (50-89\%); LTB: low TB (0-49\%); TE: transmission enhancing $(<0 \%)$.

malaria but who had not been infected at the time of the study $(\mathrm{n}=44)$, the TB activity results were $6.8 \%$ for high TB, $9.1 \%$ for intermediate blocking activity and $36.4 \%$ of low TB, with $18.1 \%$ showing an enhancing effect (Arevalo-Herrera et al. 2011). No reports are available on TB $P$. falciparum species in the region, probably due to the lower prevalence of $P$. falciparum in LA. Preliminary studies using sera collected in a village on the Colombian Pacific coast indicate that only 5\% of the sera presented fully blocked P. falciparum parasite transmission blockage $(90-100 \%)$, whereas $32.5 \%$ of them showed between $50-89 \%$ TB activity and less than half (42.5\%) showed a poorly blocked transmission, with between $0-49 \%$ blockage. In this region, both $P$. falciparum and $P$. vivax are transmitted in approximately similar proportions (Y Solarte, unpublished observations).

Evidence of the feasibility of TB vaccines - The feasibility of vaccines that block parasite transmission from humans to the mosquito vector is based on the following observations: (i) transmission blockage can be achieved by human immune mediators, such as immunoglobulins or cytokines, which are induced by parasite components expressed on the sexual parasite forms exposed to the human immune system during their circulation in the human body and (ii) as observed in nature, malaria infections are able to boost primary antibody responses against gametocytes and increase the TB effects of the corresponding sera. Immunogenic proteins that are important for parasite fertilization or other vital functions of the parasite sexual forms are considered targets for TB vaccine development (Carter et al. 2000, Stowers \& Carter 2001).
These antigens have strong potential for boosting the immune responses elicited naturally during the infection or through vaccination (Carter et al. 2000, Sattabongkot et al. 2004). Unfortunately, due to host immunological pressure these targets have the disadvantage of antigenic polymorphism (Mendis et al. 1991). In contrast, some proteins critical for parasite development and survival may only be expressed during the sporogonic cycle in the mosquito midgut (Aly et al. 2009) and will never be in contact with the human immune system. However, the vaccination of humans and animal models has indicated that these two models are able to elicit antibodies and possibly cytokines with capacity to block parasite development inside the mosquito vector (Kaslow 1990, Tsuboi et al. 2003). Likewise, molecules within the mosquito may play critical functions for parasite invasion or sporogonic development. These molecules could also be used to induce antibody production upon the vaccination of a vertebrate host and ultimately induce blockage of parasite development (Carter 2001). These vaccines would also require good formulations because none of these vaccines would either protect from the infection or reduce the disease intensity and would be considered altruistic vaccines (Wykes \& Good 2007). The vaccines would instead diminish the risk of infecting others in their immediate surrounding. This type of vaccine would have several beneficial effects. The first is prevention of the spread of the disease within the community. The second is prevention of the spread of parasites that might have evaded the effect of vaccines directed against other parasite stages, such as sporozoites and merozoites. Fi- 
nally, they would prevent the spreading of parasites resistant to drugs used for treatment of the disease (Carter 2001, Tsuboi et al. 2003).

Strategies and protein candidates for TBV development - Parasite transmission from human to human through the mosquito vector requires a sophisticated process of parasite fertilization to form zygotes, developing motile ookinetes that invade the epithelium of the mosquito midgut to form oocysts that produce thousands of sporozoites that migrate from the midgut to the salivary glands to reinitiate a new infection in the human. This complex cycle could, in principle, be interrupted in several different places (Aly et al. 2009). Although there are multiple factors in both the parasite and the vector that are required for the successful development of this cycle, learning how to interfere with this process would allow blocking of human to human parasite transmission (Ghosh et al. 2000). The most studied mechanisms for interrupting this process are immune interference of gamete fertilization, ookinete invasion, oocyst maturation and sporozoite migration and delivery (Florens et al. 2002, Lavazec $\&$ Bourgouin 2008). Bacteria and reactive oxygen species could also influence the mosquito physiology and its ability to sustain parasite development (Kumar et al. 2003). Specific recognition of sporozoites to the salivary glands, most likely via receptor-ligand interactions, may also be an immune interference target (Ghosh et al. 2001).

Although hundreds of genes have been shown to be expressed during the parasite life cycle, to date, only a few of them have been cloned and expressed and even fewer have been tested for vaccine potential. Among these proteins, some restricted to the $P$. falciparum sexual stages (Pfs230, Pfs48/45 Pfs28/Pfs25) and others to that of $P$. vivax (Pv28/25, Pvs230 and Pvs48/45) are expressed on the surface of the sexual parasite stage where they can accomplish critical functions for parasite development (Table II) (Moreira et al. 2004, Coutinho-Abreu \& Ramalho-Ortigao 2010). Some of these antigens belong to a protein superfamily characterized by conserved structures with six cystein-rich glycoprotein domains that contain an N-terminal secretory signal sequence domain followed by four similar epidermal growth factor-like domains anchored by a GPI moiety (Kaslow et al. 1988, Alejo-Blanco et al. 1999). These are conserved across Plasmodia species and highly conserved geographically (Kocken et al. 1993). Because some of these antigens are expressed on the gametocyte surface in human blood circulation, they can induce immune responses that would block their fertilization and responses against them can be boosted by repeated natural infections in endemic areas. The Pfs $48 / 45$ and Pfs 230 proteins are the major $P$. falciparum gametocyte/gamete surface antigens synthesized during early gametocyte development (Kumar $\&$ Carter 1984). A recent global analysis of the Pvs 230 gene demonstrated limited sequence polymorphism. Although there have been no reports on its immunogenicity and its role in TB efficacy, the high degree of conservation of this gene would suggest its usefulness for vaccine development (Doi et al. 2011).
Pfs $48 / 45$ is a hydrophobic glycoprotein doublet of 48 and $45 \mathrm{kDa}$, which contains six cystein-rich domains and is expressed on zygotes. It appears to be involved in the fertilization process and zygote formation (van Dijk et al. 2001).

In the context, several Plasmodium proteins have also been proposed as candidate targets for TB vaccines. Chitinases are enzymes that have been found in prokaryotes and eukaryotes and are mainly involved in cell wall modification, allowing the parasite to penetrate the chitincontaining peritrophic matrix in the mosquito midgut. Previous studies using recombinant Chitinase 1 of $P$. gallinaceum, hydrolysed polymeric chitin and derivatives of chitin oligosaccharides suggest that $P$. gallinaceum ookinetes use this enzymes to initiate mosquito midgut invasion (Vinetz et al. 2000). Other proteins, including a similar von Willebrand factor type A domain (WARP), are present as soluble products in the micronemes of the apical complex in mature ookinetes (Yuda et al. 2001) and are involved in cell-cell interactions (Colombatti et al. 1993, Lee et al. 1995). These proteins have been cloned and expressed in Plasmodium berghei, P. falciparum and P. vivax (Gholizadeh et al. 2009).

Monoclonal antibodies, titled MG25E, MG24C and MG4B, produced by immunizing mice with Anopheles gambiae midgut lysate reacted against $110 \mathrm{kDa}$ and $7 \mathrm{kDa}$ midgut antigens and have been able to block the transmission of $P$. vivax and $P$. falciparum to Anopheles stephensi, Anopheles farauti and Anopheles albimanus (Lal et al. 2001). Additionally, a novel midgut luminal surface antigen in An. gambiae, aminopeptidase N, has been characterised and shown to be indispensable to ookinete invasion. Antibodies against this protein strongly inhibited both P. falciparum and P. berghei development, marking this protein as a potential vaccine target (Dinglasan et al. 2007).

Constraints for the development of recombinant $T B$ vaccines - During the last two decades, some of these malaria antigens have been pursued as vaccine candidates and tested in animal models as well as in humans (Tsuboi et al. 2003). In P. falciparum, the Pfs 230 , Pfs 48/45, Pfs 25 and Pfs 28 antigens have been expressed as recombinant proteins, formulated with different adjuvants and tested in rodents, rabbits and primates (Hisaeda \& Yasutomo 2002, Tsuboi et al. 2003) where they induced high levels of TB antibodies (Kaslow et al. 1992, Kaslow 1996). However, the major constraint in using these proteins for TBV production is the high complexity of their structures (Chowdhury et al. 2009).

Although the expression of these cysteine-rich proteins in their proper conformation and with sufficient yield has been complicated, in a recent study, the co-expression of a truncated C-terminal fragment of Pfs $48 / 45$, that was fused with a maltose-binding protein and four proteins that acted as catalysts in protein folding (DsbA, DsbC, FkpA and SurA), resulted in the expression of correctly folded recombinant protein that generated high titres of antibody in immunized BALB/c mice and exhibited TB activity (Outchkourov et al. 2008). An expression strategy involving the har- 
TABLE II

Antigens of Plasmodium vivax and Plasmodium falciparum candidates for transmission blocking vaccine

\begin{tabular}{lccc}
\hline Plasmodium parasite & Antigen & Parasite location & Reference \\
\hline P. falciparum & Pfs230 & Gametocytes & Quakyi et al. (1987) \\
& Pfs48/45 & Gametocytes and gametes & Kocken et al. (1993a) \\
Pfs25/28 vivax & Pvs230 & Zigotes and ookinetes & Kaslow et al. (1988) \\
& Pvs48/45 & Gametocytes & Doi et al. (2011) \\
& Pvs25/28 & Gametocytes and gametes & (Not reported) \\
& Zigotes and ookinetes & Tsuboi et al. (1998) \\
\hline
\end{tabular}

monisation of codons for the translation of the protein in heterologous systems such as Escherichia coli was also recently used to produce recombinant $\mathrm{Pfs} 48 / 45$ protein. The purified protein that was recognized by MAbs directed against native epitopes of the protein and testing in mice revealed a potent TB activity ( $>$ 90\%) (Chowdhury et al. 2009).

An additional limitation in these proteins is the identification of parasite epitopes optimal for vaccine formulation. A series of MAbs directed against Pfs48/45 that recognize seven epitopes along the protein (I, IIa/IIc, IIb, III, IV and V) have displayed differential TB capacity. The MAb directed against epitope I recognized a region of 10 cysteines in the C-terminal extreme and it exhibited strong TB effects (Outchkourov et al. 2008). MAbs directed against region III did not show any effect, and targeting regions II and III only produced transmission blockage when they were administered together, showing the requirement of a synergistic effect. Moreover, although the Pfs $48 / 45$ protein as a whole is relatively well conserved, some of these epitopes appear to display low polymorphisms and the configuration of epitopes IIa (strain 7G8) and IIc (strain NF54) appear to be unique to each strain (Foo et al. 1991).

Pre-clinical studies to assess potential TB vaccine candidates - As mentioned previously, all $P$. falciparum sexual parasite antigens have been tested for their vaccine potential in different pre-clinical studies using different animal models (Kaslow 1996, Carter 2001). Recombinant versions of Pfs48/45 were initially produced and, although they displayed high immunogenicity in mice and rabbits, the elicited antibodies failed to block parasite transmission, suggesting that the recombinant proteins did not adopt the proper folding required to mimic the native epitope conformations (Milek et al. 1998).

The proper conformation of the C-terminal fragment was achieved and immunisation of BALB/c mice with the recombinant protein emulsified in Freund adjuvant generated high antibody titres ranging from 1/30,0001/300,000 with $95 \%$ TB activity when tested in An. stephensi (Outchkourov et al. 2008).

Pfs25 was expressed in Saccharomyces cerevisiae, formulated in Freund's or muramyl tripeptide adjuvant (MF59) and was used to immunize CAF1 mice by intra- peritoneal injection and Aotus vociferans by intramuscular injection. This protein did not elicit complete TB antibodies in rodents (Kaslow et al. 1994).

In another study, Pfs 25 was produced in Pichia pastoris and was conjugated to an outer-membrane protein complex of Neisseria meningitides, adsorbed on aluminium hydroxyphosphate and tested in mice, rabbit and primates. This formulation displayed better immunogenicity than formulations using the adjuvants Montanide ISA 51 and ISA720, with antibodies titres between 1/20,000-1/100,000 and a TB activity in An. stephensi of $50 \%$ (Wu et al. 2006).

P. vivax, Pvs25 and Pvs28 that had been cloned, expressed in $S$. cerevisiae and formulated with aluminium hydroxide were injected four times intraperitoneally in BALB/c, C57BL/6, A/J, B10.BR, CAF1, BALB.B and $\mathrm{C} 57 \mathrm{BL} / 10$ mice. Animals developed specific antibodies titres of between 1/20,000-1/500,000 that were able to block parasite transmission to Anopheles freeborni, An. stephensi, An. gambiae and An. farauti mosquitoes at a greater than $90 \%$ rate (Hisaeda et al. 2000). In another study using Pvs25 and an adenovirus as the adjuvant, BALB/c mice were immunized four times by different routes: intramuscular, subcutaneous and intranasal. The MFA revealed a TB activity of $99 \%$ with no significant differences between the routes of immunization (Miyata et al. 2011).

Clinical grade Pvs25 formulated with different adjuvants was also tested in different monkey species. A formulation using Montanide ISA 720 and tested in Aotus lemurinus monkeys was highly immunogenic, with a strong antibody response persisting for at least 10 months. These antibodies displayed TB activity in $A n$. albimanus tested using MFA with $P$. vivax gametocytecarrying human blood. Because this protein is expressed on the surface of ookinetes and oocysts, but not in on blood circulating parasites (gametocytes), challenging Aotus monkeys with $P$. vivax parasites did not boost the anti-Pvs25 antibody response elicited by vaccination. These results confirm that re-vaccination with these ookinete/oocyst proteins would be required for maintaining immunity in endemic areas (Arevalo-Herrera et al. 2005b). A similar vaccine formulation using Montanide ISA 720 and alum was also highly immunogenic in Rhesus (Maccaca mulata) and chimpanzee models 
and induced long-lasting TB antibodies in An. freeborni with TB activity of over $90 \%$ in the Montanide ISA 720 assays (Collins et al. 2006).

During the last decade, DNA vaccination routes have been considered as an alternative vaccination method that could potentially overcome the problems with protein folding. DNA vaccines use the host cell machinery to produce the desired proteins, which are then presented to the host immune cells in the context of the mayor complex histocompatibility class I (McDonnell \& Askari 1996). These systems have multiple advantages: first, because both Plasmodium and human proteins are expected to be properly folded and, second, because the in vivo production of the immunogen avoids the inconvenience and cost of laboratory protein production, with proper folding and easier purification and production under Good Manufacturing Practice (GMP) conditions. This process is significantly cheaper for DNA vaccines than for protein vaccines.

A Pfs25-based DNA vaccine using VR1012 and VR1020 plasmids and tested in BALB/c mice induced potent TB activity, resulting in an up to $97 \%$ decrease in oocyst numbers and a 75\% decrease in infection rates. Although these DNA vaccines elicited antibody production, they were unable to reduce the parasite infectivity however, a protein boosting immunization induced a 30 -fold increase in antibody titres and blocked $P$. falciparum transmission to mosquitoes. In view of the constraints of protein production, boosting antibody titres through parasite challenge represents a promising alternative (Lobo et al. 1999). Recently, a Pbs48/45 DNA-was tested in BALB/c mice and although antibody levels were below the level of detection [optical density $(\mathrm{OD})=0.4$ in a $1 / 50$ dilution], infection with parasites efficiently boosted this response (OD $=1.2$ in a 1/2,500 dilution) (Haddad et al. 2006).

Testing TB vaccines have an advantage, as TB efficacy can be determined using SMFA. Whereas Phase II trials to assess the efficacy of pre-erythrocytic and asexual blood stage vaccine candidates require that human volunteers be exposed to a parasite infection challenge, the efficacy of TB vaccines candidates can be easily evaluated in ex vivo assays that measure the blocking activity of the immune responses elicited by the vaccines.

Clinical development of TB vaccine candidates - Because of limitations in producing some of the antigens described above under GMP, only two TB vaccine candidates have been tested in Phase I clinical trials. In the first, Pvs25 produced in S. cerevisiae, was formulated in alhydrogel and inoculated at doses of 5,20 or $80 \mu \mathrm{g}$ by intramuscular injection in 30 naïve volunteers. The formulation was safe and immunogenic and although only a moderate antibody response was elicited, human sera partially blocked $P$. vivax transmission to mosquitoes (Malkin et al. 2003). In the second trial, P. falciparum Pfs 25 and $P$. vivax Pvs25 were evaluated in a Phase I clinical trial, in which both proteins were formulated with Montanide ISA 51. Because this formulation displayed overly strong reactogenicity, the trial had to be stopped (Wu et al. 2008).
Conclusion and perspectives - Although most studies on malaria TB immunity have focused on P. falciparum and have been carried out in Africa, growing efforts are under way that attempt to understand TB immunity against $P$. vivax in both Asia and LA. A series of studies conducted in Sri Lanka formed the basis for more recent research being carried out in LA. Here, we described studies conducted in the low and moderate malaria transmission settings of Colombia and Mexico where, as in most regions of LA, both $P$. vivax and $P$. falciparum parasites circulate simultaneously. The results of the studies focusing on P. vivax TB indicate that responses are greater than those described in Asia, with a high prevalence of sera capable of completely blocking parasite transmission to mosquitoes. These results are remarkable not only for the potential epidemiological impact of these responses in the community, but also because of their important implications for further TB vaccine deployment in this continent. Additionally, the availability of Aotus monkeys in several countries of LA region, namely Colombia, represents a valuable resource for addressing important questions regarding TB immunity that are difficult to study in human populations. Indeed, the possibility of infecting Aotus with strains of human malaria parasites capable of producing gametocytes opens the possibility of assessing questions regarding the levels priming and boosting required for the long-term maintenance of TB vaccines protective efficacy (Herrera et al. 2011).

The National Institute of Allergy and Infectious Diseases/National Institutes of Health (NIH) is currently funding the establishment of the Centro Latino Americano de Investigación en Malaria, a research network involving countries such as Colombia, Peru, Panama and Colombia. The NIH supports a network of 10 International Centres of Excellence in Malaria located across the tropical regions of LA, Africa and Asia. The availability of well-established, laboratory-reared An. albimanus mosquito colonies with capacities for carrying out MFA to assess TB activity (using both malaria-infected human samples from endemic regions and samples from non-human primates in different countries of the LA region) may allow for a valuable contribution of the region to malaria elimination in other areas of the planet.

\section{ACKNOWLEDGEMENTS}

To the participation of endemic communities from malaria endemic areas of Colombia, who kindly accepted to participate in part of the studies mentioned here, to Programa de Enfermidades Tropicales, Instituto de Salud del Pacífico, and to Paola Rojas, for her technical support to prepare this manuscript.

\section{REFERENCES}

Alejo-Blanco AR, Paez A, Gerold P, Dearsly AL, Margos G, Schwardz RT, Barker G, Rodriguez MC, Sinden RE 1999. The biosynthesis and post-translational modification of Pbs21, an ookinete surface protein of Plasmodium berghei. Mol Biochem Parasitol 98: 163-173.

A1-Olayan EM, Williams GT, Hurd H 2002. Apoptosis in the malaria protozoan, Plasmodium berghei: a possible mechanism for limiting intensity of infection in the mosquito. Int J Parasitol 32: 1133-1143. 
Alonso PL, Ballou R, Brown G, Chitnis C, Loucq C, Moorthy V, Saul A, Wirth D 2011a. A research agenda for malaria eradication: vaccines. PLoS Med 8: e1000398.

Alonso PL, Brown G, Arevalo-Herrera M, Binka F, Chitnis C, Collins F, Doumbo OK, Greenwood B, Hall BF, Levine MM, Mendis K, Newman RD, Plowe CV, Rodriguez MH, Sinden R, Slutsker L, Tanner M 2011b. A research agenda to underpin malaria eradication. PLoS Med 8: e1000406.

Aly AS, Vaughan AM, Kappe SH 2009. Malaria parasite development in the mosquito and infection of the mammalian host. Annu Rev Microbiol 63: 195-221.

Arevalo-Herrera M, Castellanos A, Yazdani SS, Shakri AR, Chitnis CE, Dominik R, Herrera S 2005a. Immunogenicity and protective efficacy of recombinant vaccine based on the receptor-binding domain of the Plasmodium vivax Duffy binding protein in Aotus monkeys. Am J Trop Med Hyg 73: 25-31.

Arevalo-Herrera M, Solarte Y, Rocha L, Alvarez D, Beier JC, Herrera S 2011. Characterization of Plasmodium vivax transmissionblocking activity in low to moderate malaria transmission settings of the Colombian Pacific coast. Am J Trop Med Hyg 84: 71-77.

Arevalo-Herrera M, Solarte Y, Yasnot MF, Castellanos A, Rincon A, Saul A, Mu J, Long C, Miller L, Herrera S 2005b. Induction of transmission-blocking immunity in Aotus monkeys by vaccination with a Plasmodium vivax clinical grade Pvs25 recombinant protein. Am J Trop Med Hyg 73: 32-37.

Arevalo-Herrera M, Solarte Y, Zamora F, Mendez F, Yasnot MF, Rocha L, Long C, Miller LH, Herrera S 2005c. Plasmodium vivax: transmission-blocking immunity in a malaria-endemic area of Colombia. Am J Trop Med Hyg 73: 38-43.

Boudin C, Diop A, Gaye A, Gadiaga L, Gouagna C, Safeukui I, Bonnet S 2005. Plasmodium falciparum transmission blocking immunity in three areas with perennial or seasonal endemicity and different levels of transmission. Am J Trop Med Hyg 73: 1090-1095.

Boudin C, Van Der Kolk M, Tchuinkam T, Gouagna C, Bonnet S, Safeukui I, Mulder B, Meunier JY, Verhave JP 2004. Plasmodium falciparum transmission blocking immunity under conditions of low and high endemicity in Cameroon. Parasite Immunol 26: 105-110.

Bousema T, Roeffen W, Meijerink H, Mwerinde H, Mwakalinga S, van Gemert GJ, van de Vegte-Bolmer M, Mosha F, Targett G, Riley EM, Sauerwein R, Drakeley C 2010. The dynamics of naturally acquired immune responses to Plasmodium falciparum sexual stage antigens Pfs $230 \& \mathrm{Pfs} 48 / 45$ in a low endemic area in Tanzania. PLoS ONE 5: e14114.

Bousema T, Sutherland CJ, Churcher TS, Mulder B, Gouagna LC, Riley EM, Targett GA, Drakeley CJ 2011. Human immune responses that reduce the transmission of Plasmodium falciparum in African populations. Int J Parasitol 41: 293-300.

Cao YM, Tsuboi T, Torii M 1998. Nitric oxide inhibits the development of Plasmodium yoelii gametocytes into gametes. Parasitol Int 47: 157-166.

Carter R 2001. Transmission blocking malaria vaccines. Vaccine 19: 2309-2314.

Carter R, Graves P, Keister DB, Quakyi I 1990. Properties of epitopes of Pfs $48 / 45$, a target of transmission blocking monoclonal antibodies, on gametes of different isolates of Plasmodium falciparum. Parasit Immunol 12: 587-603.

Carter R, Mendis K 1992. Transmission immunity in malaria: reflections on the underlying immune mechanisms during natural infections and following artificial immunization. Mem Inst Oswaldo Cruz 87 (Suppl. III): 169-173.

Carter R, Mendis KN, Miller LH, Molineaux L, Saul A 2000. Malaria transmission-blocking vaccines-how can their development be supported? Nat Med 6: 241-244.
Chowdhury DR, Angov E, Kariuki T, Kumar N 2009. A potent malaria transmission blocking vaccine based on codon harmonized full length Pfs $48 / 45$ expressed in Escherichia coli. PLoS ONE 4: e6352.

Collins WE, Barnwell JW, Sullivan JS, Nace D, Williams T, Bounngaseng A, Roberts J, Strobert E, McClure H, Saul A, Long CA 2006. Assessment of transmission-blocking activity of candidate Pvs25 vaccine using gametocytes from chimpanzees. Am J Trop Med Hyg 74: 215-221.

Colombatti A, Bonaldo P, Dolian R 1993. Type A modules: interacting domains found in several non-fibrillar collagens and in other extracellular matrix proteins. Matrix 13: 297-306.

Coutinho-Abreu IV, Ramalho-Ortigao M 2010. Transmission blocking vaccines to control insect-borne diseases - A Review. Mem Inst Oswaldo Cruz 105: 1-12.

Dawes EJ, Churcher TS, Zhuang S, Sinden RE, Basanez MG 2009. Anopheles mortality is both age- and Plasmodium-density dependent: implications for malaria transmission. Malar J 8: 228.

Dinglasan RR, Kalume DE, Kanzok SM, Ghosh AK, Muratova O, Pandey A, Jacobs-Lorena M 2007. Disruption of Plasmodium falciparum development by antibodies against a conserved mosquito midgut antigen. Proc Natl Acad Sci USA 104: 13461-13466.

Doi M, Tanabe K, Tachibana S, Hamai M, Tachibana M, Mita T, Yagi M, Zeyrek FY, Ferreira MU, Ohmae H, Kaneko A, Randrianarivelojosia M, Sattabongkot J, Cao YM, Horii T, Torii M, Tsuboi T 2011. Worldwide sequence conservation of transmission-blocking vaccine candidate Pvs230 in Plasmodium vivax. Vaccine 29: 4308-4315.

Doolan DL, Hoffman SL 2001. DNA-based vaccines against malaria: status and promise of the Multi-Stage Malaria DNA Vaccine Operation. Int J Parasitol 31: 753-762.

Eksi S, Czesny B, van Gemert GJ, Sauerwein RW, Eling W, Williamson KC 2006. Malaria transmission-blocking antigen, Pfs230, mediates human red blood cell binding to exflagellating male parasites and oocyst production. Mol Microbiol 61: 991-998.

Fanning SL, Czesny B, Sedegah M, Carucci DJ, G-J G, Eling W, Williamson KC 2003. A glycosylphosphatidylinositol anchor signal sequence enhances the immunogenicity of a DNA vaccine encoding Plasmodium falciparum sexual-stage antigen, Pfs230. Vaccine 21: 3228-3225.

Feachem RG, Phillips AA 2009. Malaria: 2 years in the fast lane. Lancet 373: 1409-1411.

Florens L, Washburn MP, Raine JD, Anthony RM, Grainger M, Haynes JD, Moch JK, Muster N, Sacci JB, Tabb DL, Witney AA, Wolters D, Wu Y, Gardner MJ, Holder AA, Sinden RE, Yates JR, Carucci DJ 2002. A proteomic view of the Plasmodium falciparum life cycle. Nature 419: 520-526.

Foo A, Carter R, Lambros C, Graves P, Quakyi I, Targett GTA, Ponnudurai T, Lewis GE 1991. Conserved and variant epitopes of target antigens of transmission-blocking antibodies among isolates of Plasmodium falciparum from Malaysia. Am J Trop Med Hyg 44: 623-631.

Gamage-Mendis AC, Rajakaruna J, Carter R, Mendis KN 1992. Transmission blocking immunity to human Plasmodium vivax malaria in an endemic population in Kataragama, Sri Lanka. Parasit Immunol 14: 385-396.

Genton B, D'Acremont V, Rare L, Baea K, Reeder JC, Alpers MP, Muller I 2008. Plasmodium vivax and mixed infections are associated with severe malaria in children: a prospective cohort study from Papua New Guinea. PLoS Med 5: e127.

Gholizadeh S, Djadid ND, Basseri HR, Zakeri S, Ladoni H 2009. Analysis of von Willebrand factor A domain-related protein 
(WARP) polymorphism in temperate and tropical Plasmodium vivax field isolates. Malar J 8: 137.

Ghosh A, Edwards MJ, Jacobs-Lorena M 2000. The journey of the malaria parasite in the mosquito: hopes for the new century. Parasitol Today 16: 196-201.

Ghosh AK, Ribolla PE, Jacobs-Lorena M 2001. Targeting Plasmodium ligands on mosquito salivary glands and midgut with a phage display peptide library. Proc Natl Acad Sci USA 98: 13278-13281.

Girard MP, Reed ZH, Friede M, Kieny MP 2007. A review of human vaccine research and development: malaria. Vaccine 25: $1567-1580$.

Greenwood BM, Bojang K, Whitty CJ, Targett GA 2005. Malaria. Lancet 365: 1487-1498.

Greenwood BM, Fidock DA, Kyle DE, Kappe SH, Alonso PL, Collins FH, Duffy PE 2008. Malaria: progress, perils, and prospects for eradication. J Clin Invest 118: 1266-1276.

Grotendorst CA, Carter R 1987. Complement effects of the infectivity of Plasmodium gallinaceum to Aedes aegypti mosquitoes. II. Changes in sensitivity to complement-like factors during zygote development. J Parasitol 73: 980-984.

Grotendorst CA, Carter R, Rosenberg R, Koontz LC 1986. Complement effects on the infectivity of Plasmodium gallinaceum to Aedes aegypti mosquitoes. I. Resistance of zygotes to the alternative pathway of complement. J Immunol 136: 4270-4274.

Guerra CA, Gikandi PW, Tatem AJ, Noor AM, Smith DL, Hay SI, Snow RW 2008. The limits and intensity of Plasmodium falciparum transmission: implications for malaria control and elimination worldwide. PLoS Med 5: e38.

Haddad D, Maciel J, Kumar N 2006. Infection with Plasmodium berghei boosts antibody responses primed by a DNA vaccine encoding gametocyte antigen Pbs48/45. Infect Immun 74: 2043-2051.

Healer J, McGuinness D, Carter R, Riley E 1999. Transmission-blocking immunity to Plasmodium falciparum in malaria-immune individuals is associated with antibodies to the gamete surface protein Pfs230. Parasitology 119: 425-433.

Herrera S, Rodriguez D, Acero D, Ocampo V, Arévalo-Herrera M 2011. Platform for Plasmodium vivax vaccine discovery and development. Mem Inst Oswaldo Cruz 106 (Suppl. I): 179-192.

Hisaeda H, Stowers AW, Tsuboi T, Collins WE, Sattabongkot JS, Suwanabun N, Torii M, Kaslow DC 2000. Antibodies to malaria vaccine candidates Pvs 25 and Pvs 28 completely block the ability of Plasmodium vivax to infect mosquitoes. Infect Immun 68: 6618-6623.

Hisaeda H, Yasutomo K 2002. Development of malaria vaccines that block transmission of parasites by mosquito vectors. $J$ Med Invest 49: 118-123.

Kaslow DC 1990. Immunogenicity of Plasmodium falciparum sexual stage antigens: implications for the design of a transmission blocking vaccine. Immunol Lett 25: 83-86.

Kaslow DC 1996. Transmission blocking vaccines. In SL Hofman (ed.), Malaria vaccine development, ASM Press, Washington, p. 181-228.

Kaslow DC, Bathurst IC, Barr PJ 1992. Malaria transmission-blocking vaccines. Tibtech 10: 388-391.

Kaslow DC, Bathurst IC, Lensen T, Ponnudurai T, Barr PJ, Keister DB 1994. Saccharomyces cerevisiae recombinant Pfs 25 adsorbed to alum elicits antibodies that block transmission of Plasmodium falciparum. Infect Immun 62: 5576-5580.

Kaslow DC, Quakyi IA, Syin C, Raum MG, Keister DB, Coligan JE, McCutchan TF, Miller LH 1988. A vaccine candidate from the sexual stage of human malaria that contains EGF-like domains. Nature 333: 74-76.
Kaslow DC, Shiloach J 1994. Production, purification and immunogenicity of a malaria transmission-blocking vaccine candidate: TBV25H expressed in yeast and purified using nickel-NTA agarose. Biotech 12: 494-499.

Kelly-Hope L, Ranson H, Hemingway J 2008. Lessons from the past: managing insecticide resistance in malaria control and eradication programmes. Lancet Infect Dis 8: 387-389.

Kocken CH, Jansen J, Kaan AM, Beckers PJ, Ponnudurai T, Kaslow DC, Konings RN, Schoenmakers JG 1993. Cloning and expression of the gene coding for the transmission blocking target antigen Pfs 48/45 of Plasmodium falciparum. Mol Biochem Parasitol 61: 59-68.

Kumar N, Carter R 1984. Biosynthesis of the target antigens of antibodies blocking transmission of Plasmodium falciparum. Mol Biochem Parasitol 13: 333-342.

Kumar S, Christophides GK, Cantera R, Charles B, Han YS, Meister S, Dimopoulos G, Kafatos FC, Barillas-Mury C 2003. The role of reactive oxygen species on Plasmodium melanotic encapsulation in Anopheles gambiae. Proc Natl Acad Sci USA 100: 14139-14144.

Lal AA, Patterson PS, Sacci JB, Vaughan JA, Paul C, Collins WE, Wirtz RA, Azad AF 2001. Anti-mosquito midgut antibodies block development of Plasmodium falciparum and Plasmodium vivax in multiple species of Anopheles mosquitoes and reduce vector fecundity and survivorship. Proc Natl Acad Sci 98: 5228-5233.

Lavazec C, Bourgouin C 2008. Mosquito-based transmission blocking vaccines for interrupting Plasmodium development. Microbes Infect 10: 845-849.

Lee JO, Rieu P, Arnaout MA, Liddington R 1995. Crystal structure of the A domain from the alpha subunit of integrin CR3 (CD11b/ CD18). Cell 80: 631-638.

Lobo CA, Dhar R, Kumar N 1999. Immunization of mice with DNAbased Pfs 25 elicits potent malaria transmission-blocking antibodies. Infect Immun 67: 1688-1693.

Luckhart S, Vodovotz Y, Cui L, Rosenberg R 1998. The mosquito Anopheles stephensi limits malaria parasite development with inducible synthesis of nitric oxide. Proc Natl Acad Sci 95: 5700-5705.

Malkin EM, Durbin AP, Diemert DJ, Sattabongkot J, Wu Y, Miura K, Long CA, Lambert L, Miles AP, Wang J, Stowers A, Miller LH, Saul A 2003. Phase I trial of Pvs25H: a transmission blocking vaccine for Plasmodium vivax malaria. Vaccine 23: 3131-3138.

McDonnell WM, Askari FK 1996. DNA vaccines. N Engl J Med 334: 42-45.

Mendis C, Munesinghe YD, de Silva YNY, Keragalla I, Carter R 1987. Malaria transmission-blocking immunity induced by natural infections of Plasmodium vivax in humans. Infect Immun 55: 369-372.

Mendis KN, David PH, Carter R 1991. Antigenic polymorphism in malaria: is it an important mechanism for immune evasion? Immunol Today 12: A34-37.

Milek RL, Roeffen WF, Kocken CH, Jansen J, Kaan AM, Eling WM, Sauerwein RW, Konings RN 1998. Immunological properties of recombinant proteins of the transmission blocking vaccine candidate, Pfs $48 / 45$, of the human malaria parasite Plasmodium falciparum produced in Escherichia coli. Parasit Immunol 20: 377-385.

Miyata T, Harakuni T, Sugawa H, Sattabongkot J, Kato A, Tachibana M, Torii M, Tsuboi T, Arakawa T 2011. Adenovirus-vectored Plasmodium vivax ookinete surface protein, Pvs25, as a potential transmission-blocking vaccine. Vaccine 29: 2720-2726.

Moorthy VS, Good MF, Hill AV 2004. Malaria vaccine developments. Lancet 363: 150-156.

Moreira CK, Marrelli MT, Jacobs-Lorena M 2004. Gene expression in Plasmodium: from gametocytes to sporozoites. Int J Parasitol 34: 1431-1440. 
Mulder B, Lensen T, Tchuinkam T, Roeffen W, Verhave JP, Boudin C, Sauerwein R 1999. Plasmodium falciparum: membrane feeding assays and competition ELISAs for the measurement of transmission reduction in sera from Cameroon. Exp Parasitol 92: 81-86.

Naotunne TdS, Karunaweera N, Mendis KN, Carter R 1993. Cytokine-mediated inactivation of malarial gametocytes is dependent on the presence of white cells. Immunol 78: 555-562.

Naotunne TS, Karunaweera ND, Del Giudice G, Kularatne MU, Grau GE, Carter R, Mendis KN 1991. Cytokines kill malaria parasites during infection crisis: extracellular complementary factors are essential. J Exp Med 173: 523-529.

Outchkourov NS, Roeffen W, Kaan A, Jansen J, Luty A, Schuiffel D, van Gemert GJ, van de Vegte-Bolmer M, Sauerwein RW, Stunnenberg HG 2008. Correctly folded Pfs $48 / 45$ protein of Plasmodium falciparum elicits malaria transmission-blocking immunity in mice. Proc Natl Acad Sci USA 105: 4301-4305.

Peiris JS, Premawansa S, Ranawaka MB, Udagama PV, Munasinghe YD, Nanayakkara MV, Gamage CP, Carter R, David PH, Mendis KN 1988. Monoclonal and polyclonal antibodies both block and enhance transmission of human Plasmodium vivax malaria. Am J Trop Med Hyg 39: 26-32.

Premawansa S, Gamage-Mendis A, Perera L, Begarnie S, Mendis K, Carter R 1994. Plasmodium falciparum malaria transmissionblocking immunity under conditions of low endemicity as in Sri Lanka. Parasite Immunol 16: 35-42.

Quakyi IA, Carter R, Rener J, Kumar N, Good MF, Miller LH 1987. The 230-kDa gamete surface protein of Plasmodium falciparum is also a target for transmission-blocking antibodies. J Immunol 139: 4213-4217.

Ramsey JM, Salinas E, Rodriguez MH 1996. Acquired transmissionblocking immunity to Plasmodium vivax in a population of southern coastal Mexico. Am J Trop Med Hyg 54: 458-463.

Ranawaka MB, Munesinghe YD, da Silva DMR, Carter R, Mendis KN 1988. Boosting of transmission blocking immunity during natural Plasmodium vivax infection in humans depends upon frequent reinfection. Infect Immun 56: 1820-1824.

Read D, Lensen AH, Begarnies S, Haley S, Raza A, Carter R 1994. Transmission-blocking antibodies against multiple, non-variant target epitopes of the Plasmodium falciparum gamete surface antigen Pfs230 are all complement-fixing. Parasit Immunol 16: 511-519.

Reed ZH, Friede M, Kieny MP 2006. Malaria vaccine development: progress and challenges. Curr Mol Med 6: 231-245.

Richie TL, Saul A 2002. Progress and challenges for malaria vaccines. Nature 415: 694-701.

Roeffen W, Beckers PJA, Tecien K, Lensen T, Sauerwein RW, Meuwissen JHET, Eling W 1995. Plasmodium falciparum: a comparison of the activity of Pfs230-specific antibodies in an assay of transmission-blocking immunity and specific competition ELISAs. Exp Parasitol 80: 15-26.

Sattabongkot J, Tsuboi T, Zollner GE, Sirichaisinthop J, Cui L 2004. Plasmodium vivax transmission: chances for control? Trends Parasitol 20: 192-198.

Sinden RE 2010. A biologist's perspective on malaria vaccine development. Hum Vaccin 6: 3-11.

Smith TA, Chitnis N, Briet OJ, Tanner M 2011. Uses of mosquitostage transmission-blocking vaccines against Plasmodium falciparum. Trends Parasitol 27: 190-196.
Snounou G 2004. Cross-species regulation of Plasmodium parasitaemia cross-examined. Trends Parasitol 20: 262-265.

Solarte Y, Manzano MR, Rocha L, Hurtado H, James MA, ArevaloHerrera M, Herrera S 2011. Plasmodium vivax sporozoite production in Anopheles albimanus mosquitoes for vaccine clinical trials. Am J Trop Med Hyg 84: 28-34.

Stowers A, Carter R 2001. Current developments in malaria transmission-blocking vaccines. Expert Opin Biol Ther 1: 619-628.

Sutherland CJ 2009. Surface antigens of Plasmodium falciparum gametocytes: a new class of transmission-blocking vaccine targets? Mol Biochem Parasitol 166: 93-98.

Targett GA, Greenwood BM 2008. Malaria vaccines and their potential role in the elimination of malaria. Malar 7 (Suppl. 1): S10.

Touray MG, Seeley DC, Jr., Miller LH 1994. Plasmodium gallinaceum: differential lysis of two developmental stages of malaria sporozoites by the alternative pathway of complement. Exp Parasitol 78: 294-301.

Tsuboi T, Kaslow DC, Gozar MM, Tachibana M, Cao YM, Torii M 1998. Sequence polymorphism in two novel Plasmodium vivax ookinete surface proteins, Pvs25 and Pvs28, that are malaria transmission-blocking vaccine candidates. Mol Med 4: 772-782.

Tsuboi T, Tachibana M, Kaneko O, Torii M 2003. Transmission-blocking vaccine of Plasmodium vivax malaria. Parasitol Int 52: 1-11.

van der Kolk M, De Vlas SJ, Saul A, van de Vegte-Bolmer M, Eling WM, Sauerwein RW 2005. Evaluation of the standard membrane feeding assay (SMFA) for the determination of malaria transmission-reducing activity using empirical data. Parasitology 130: 13-22.

van Dijk MR, Janse CJ, Thompson J, Waters AP, Braks JA, Dodemont HJ, Stunnenberg HG, van Gemert GJ, Sauerwein RW, Eling W 2001. A central role for P48/45 in malaria parasite male gamete fertility. Cell 104: 153-164.

Vinetz JM, Valenzuela JG, Specht CA, Aravind L, Langer RC, Ribeiro JM, Kaslow DC 2000. Chitinases of the avian malaria parasite Plasmodium gallinaceum, a class of enzymes necessary for parasite invasion of the mosquito midgut. J Biol Chem 275: 10331-10341.

WHO - World Health Organization 2010. World malaria report, WHO, Geneva, Available from: who.int/malaria/world_malaria_ report_2010/en/index.html.

Wu Y, Ellis RD, Shaffer D, Fontes E, Malkin EM, Mahanty S, Fay MP, Narum D, Rausch K, Miles AP, Aebig J, Orcutt A, Muratova O, Song G, Lambert L, Zhu D, Miura K, Long C, Saul A, Miller LH, Durbin AP 2008. Phase 1 trial of malaria transmission blocking vaccine candidates Pfs 25 and Pvs 25 formulated with montanide ISA 51. PLoS ONE 3: e2636.

Wu Y, Przysiecki C, Flanagan E, Bello-Irizarry SN, Ionescu R, Muratova O, Dobrescu G, Lambert L, Keister D, Rippeon Y, Long CA, Shi L, Caulfield M, Shaw A, Saul A, Shiver J, Miller LH 2006. Sustained high-titer antibody responses induced by conjugating a malarial vaccine candidate to outer-membrane protein complex. Proc Natl Acad Sci USA 103: 18243-18248.

Wykes M, Good MF 2007. A case for whole-parasite malaria vaccines. Int J Parasitol 37: 705-712.

Yuda M, Yano K, Tsuboi T, Torii M, Chinzei Y 2001. von Willebrand factor A domain-related protein, a novel microneme protein of the malaria ookinete highly conserved throughout Plasmodium parasites. Mol Biochem Parasitol 116: 65-72. 